\title{
The effect of friction stir welding parameters on microstructure and fatigue strength of CuZn37 brass alloys
}

\author{
A. $\mathrm{Ozer}^{1 *}, \mathrm{~A} . \mathrm{Sik}^{2}$, B. $\mathrm{Cevik}^{3}, \mathrm{M} . \mathrm{Ozer}^{4}$ \\ ${ }^{1}$ Gazi University Technical Sciences Vocational School, 06374 Ostim, Yenimahalle, Ankara, Turkey \\ ${ }^{2}$ Gazi University Faculty of Architecture Department of Industrial Design, 06570 Maltepe, Ankara, Turkey \\ ${ }^{3}$ Düzce University Gümüşova Vocational School, Department of Welding Technology, 81850 Gümüşova, Düzce, Turkey \\ ${ }^{4}$ Gazi University Faculty of Technology, Department of Metallurgical and Materials Engineering, \\ 0650 Besevler, Ankara, Turkey
}

Received 15 February 2016, received in revised form 19 April 2016, accepted 3 June 2016

\begin{abstract}
In this study, CuZn37 plates were joined by using friction stir welding. Welding was performed at a rotational speed of $750 \mathrm{rpm}$ and a welding speed of $20 \mathrm{~mm} \mathrm{~min}^{-1}$, and at a rotational speed of $1000 \mathrm{rpm}$ and welding speeds of $20,40,60 \mathrm{~mm} \mathrm{~min}^{-1}$. The welded samples were analyzed at the macro-microstructural level. Moreover, both hardness and fatigue tests were performed on samples. At the end of the macrostructural examination of the samples welded at the rotational speed of $1000 \mathrm{rpm}$ and the welding speed of $20 \mathrm{~mm} \mathrm{~min}^{-1}$, the formation of tunnel defects was observed. While the best fatigue life results at low strain rates were obtained in the samples joined at the rotational speed of $750 \mathrm{rpm}$ and the welding speed of $20 \mathrm{~mm} \mathrm{~min}^{-1}$, those at high strain rates were obtained in the samples joined at the rotational speed of $1000 \mathrm{rpm}$ and the welding speed of $60 \mathrm{~mm} \mathrm{~min}^{-1}$.
\end{abstract}

K e y words: friction stir welding, fatigue test, brass, microstructure

\section{Introduction}

Brass is an engineering material widely applied in industries due to its certain properties such as corrosion resistance, high electric and heat conductivity, easy malleability and aesthetic appearance $[1,2]$. It is difficult to weld brass components by using conventional welding processes. While copper $(\mathrm{Cu})$ melts at $\sim 1083^{\circ} \mathrm{C}$ and boils at $\sim 2562^{\circ} \mathrm{C}$, zinc (Zn) melts at $\sim 420^{\circ} \mathrm{C}$ and boils at $\sim 907^{\circ} \mathrm{C}[2,3]$. When they are welded by using conventional processes, the temperature of the welding zone exceeds the boiling point of $\mathrm{Zn}$ by leading to the evaporation of $\mathrm{Zn}$ and porosity at the weld joint [4]. The decrease in the amount of $\mathrm{Zn}$ element causes brass to lose its mechanical properties [3-6].

Brass alloys are usually joined by hard soldering. In recent years, studies have been conducted on weldability of brass alloys by using solid state welding processes [7]. The use of conventional fusion welding processes in the joining of brass alloys generates the problems of zinc evaporation and microporosity in the welds. Both problems have a considerable effect on microstructure and physical, chemical, and mechanical properties of the welding zone [2]. Therefore, different welding techniques that will prevent or reduce such welding defects are required. Friction stir welding is one of these techniques. Friction stir welding (FSW) is a solid-state welding technique invented in the Welding Institute of the UK (Cambridge-TWI) in 1991 [8, 9]. FSW is an alternative to the conventional arc welding technique with unique advantages such as the requirement of minimum surface preparation, control of welding parameters, joining of similar or dissimilar metals that are hard to weld, and no requirement of shielding gas or additional metal [9-11]. FSW is successfully used especially in joining materials such as aluminum, copper, and magnesium which are difficult to weld by using conventional arc welding methods $[6,9,10]$.

The number of studies conducted on weldability of brass alloys by using FSW method has increased in

*Corresponding author: tel.: +90 312 3548401; fax: +90 312 3543835; e-mail address: alpiozer@gmail.com 
Table 1. Chemical composition, physical and mechanical properties of the CuZn37 brass alloy

\begin{tabular}{|c|c|c|c|c|}
\hline \multicolumn{5}{|c|}{ Chemical composition (wt.\%) } \\
\hline $\mathrm{Cu}$ & $\mathrm{Zn}$ & $\mathrm{Pb}$ & $\mathrm{Fe}$ & \\
\hline 63.151 & 36.63 & 0.132 & 0.087 & \\
\hline \multicolumn{5}{|c|}{ Physical properties } \\
\hline $\begin{array}{l}\text { Density } \\
\left(\mathrm{g} \mathrm{cm}^{-3}\right)\end{array}$ & $\begin{array}{l}\text { Melting point } \\
\left({ }^{\circ} \mathrm{C}\right)\end{array}$ & $\begin{array}{c}\text { Thermal expansion } \\
\text { at } 20^{\circ} \mathrm{C} \\
\left(10^{-6} \mathrm{~K}^{-1}\right)\end{array}$ & $\begin{array}{l}\text { Modulus of } \\
\text { elasticity } \\
(\mathrm{GPa})\end{array}$ & $\begin{array}{c}\text { Thermal } \\
\text { conductivity } \\
\left(\mathrm{W} \mathrm{mK}^{-1}\right)\end{array}$ \\
\hline 8.44 & 916 & 20.5 & 103.4 & 116 \\
\hline \multicolumn{5}{|c|}{ Mechanical properties } \\
\hline $\begin{array}{l}\text { Yield strength } \\
\text { Rp0.2, min } \\
\quad(\mathrm{MPa})\end{array}$ & $\begin{array}{l}\text { Tensile strength } \mathrm{Rm} \\
(\mathrm{MPa})\end{array}$ & $\begin{array}{c}\text { Elongation A50 min } \\
(\%)\end{array}$ & Hardness $\mathrm{HR}_{\mathrm{B}}$ & \\
\hline$>170$ & $350-440$ & 19 & $50-60$ & \\
\hline
\end{tabular}

the recent years. Xie et al. [2] joined 5-mm-thick brass $(\mathrm{CuZn38})$ plates by using FSW at various rotational speeds and examined the microstructural evolution and mechanical properties of the brass joints. They reported that rotational speed was a parameter having a noticeable effect on the microstructure of weld zone and increasing rotational speed decreased the average grain size of the weld nugget. Moreover, they indicated that increasing rotational speed decreased the yield strength, but increased the percent elongation of the welded samples. Çam et al. [5] applied FSW to 3-mm-thick brass (CuZn37) plates at different rotational and welding speeds. They reported a decrease in the average grain size of the weld nugget and an increase in the tensile strength with increasing welding speed. Moghaddam et al. [12] joined 5-mm-thick brass $(\mathrm{CuZn30})$ plates by using FSW at a constant rotational speed and different welding speeds and examined mechanical and microstructure properties of the welded alloys. They found that the microstructure showed finer grains in the weld nugget compared to the base metal. They also reported that increasing welding speed led to an increase in the yield strength, but a decrease in the percent elongation. Meran [13] also applied FSW procedure to 3 -mm-thick brass (CuZn30) plates at a constant rotational speed and different welding speeds and examined its mechanical and microstructure properties. In the study, microstructural defects at low welding speeds and less penetration at high welding speeds were reported. The study also revealed that better appearance of weld nugget was obtained at medium speed and the tensile strength increased with increasing welding speed. Park et al. [14] applied FSW to 2-mm-thick brass $(\mathrm{CuZn40)}$ plates at different rotational and welding speeds and examined the mechanical and microstructural properties of the welded plates. They reported penetration defects on welded plates at low rotational and high welding speeds. They also found that increasing welding speed had a decreasing impact on the average grain size of the weld nugget. Their study also revealed that as the welding speed increased, yield and tensile strength increased and percent elongation decreased.

In this study, cold-rolled CuZn37 alloy plates were joined by using FSW process and the effects of the selected experiment parameters on microstructural properties, hardness, and fatigue strength of the welded joints were examined.

\section{Materials and methods}

In this study, cold-rolled CuZn37 brass alloy plates, which had a thickness of $4 \mathrm{~mm}$, a width of $125 \mathrm{~mm}$ and a length of $200 \mathrm{~mm}$, were used. Table 1 shows the chemical composition, physical and mechanical properties of the CuZn37 brass alloy.

During FSW process, a stirring tool with a changeable and adjustable-length pin was used. The tool shoulder was made from X210Cr12 tool steel and had a hardness of $50 \mathrm{HR}_{\mathrm{C}}$. The tool had an M6 $\times 1 \mathrm{HSS}$ tapered cylindrical pin at a tilt angle of $2^{\circ}$. The diameter of tool shoulder was $20 \mathrm{~mm}$, and the pin height was $3.8 \mathrm{~mm}$. Figure 1 shows the schematic drawing of the stirring tool.

FSW was performed at the constant shoulder plunge depth of $0.2 \mathrm{~mm}$. Table 2 shows FSW process parameters and the sample illustrations. Microstruc- 


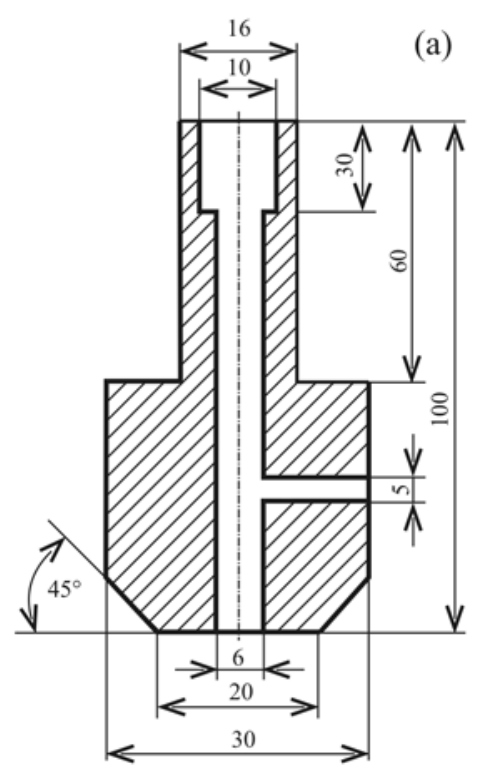

(b)

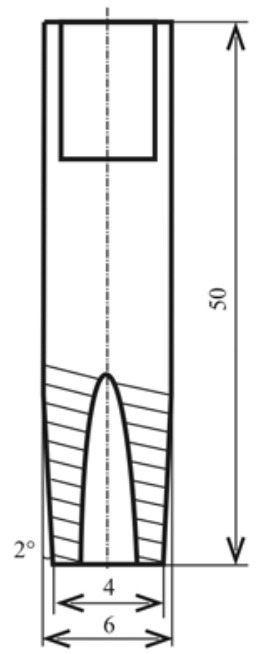

Fig. 1. Stirring tool: (a) shoulder, (b) pin.

Table 2. FSW process parameters and specimen notations

\begin{tabular}{ccc}
\hline Specimen notation & $\begin{array}{c}\text { Rotational speed } \\
(\mathrm{rpm})\end{array}$ & $\begin{array}{c}\text { Welding speed } \\
\left(\mathrm{mm} \mathrm{min}^{-1}\right)\end{array}$ \\
\hline $750 / 20$ & 750 & 20 \\
$1000 / 20$ & 1000 & 20 \\
$1000 / 40$ & 1000 & 40 \\
$1000 / 60$ & 1000 & 60 \\
\hline
\end{tabular}

tural properties, hardness, and fatigue behavior of the FSW samples were determined by using metallographic and mechanical tests. For this purpose, the samples were cross-sectioned perpendicular to the welding direction and prepared for metallographic inspection, and then etched with a solution of $100 \mathrm{ml}$ distilled $\mathrm{H}_{2} \mathrm{O}, 30 \mathrm{ml} \mathrm{HCl}$, and $5 \mathrm{~g} \mathrm{FeCl}_{3}$. Optical microscopy was used to examine the microstructure of the FSW samples. Hardness test was performed under a load of $100 \mathrm{kgf}$ by using a $1 / 16$ " steel ball for $10 \mathrm{~s}$. The samples were prepared for bending fatigue test in accordance with DIN 50142 (Fig. 2). Surface

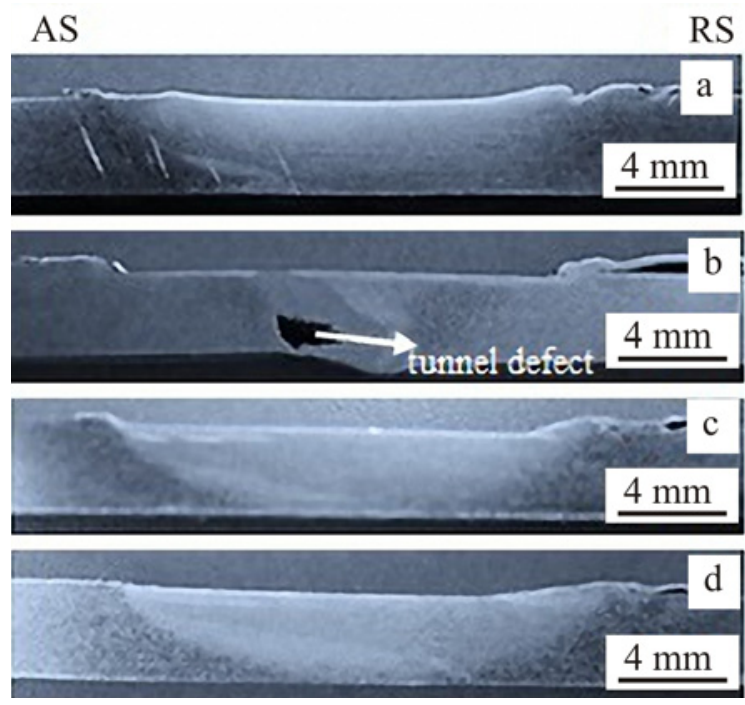

Fig. 3. Macrographs of FSW CuZn37 joints: (a) 750/20, (b) $1000 / 20$, (c) 1000/40, and (d) 1000/60 (AS is advancing side, $\mathrm{RS}$ is retreating side).

fracture analysis of the samples was performed by using a scanning electron microscope (SEM).

\section{Results and discussion}

\subsection{Macro- and microstructural examinations}

Figure 3 shows the cross-sectional macrographs of the FSW CuZn37 joints. A tunnel defect was detected on sample 1000/20 (Fig. 3b). The reasons for the formation of tunnel defect involved heat input, stirring tool design, pin design, and the imbalance in the ratio of rotational speed to welding speed $[3,5,12,13]$. In this study, all parameters were kept constant except for the rotational and welding speeds. Therefore, it could be asserted that the reason for the formation of the tunnel defect observed in sample $1000 / 20$ was the imbalance between the rotational speed and welding speed. Compared to the rotational speed, lower welding speed in sample 1000/20 caused the formation of the tunnel defect in the weld as a result of the transfer of an excessive amount of metal from the weld root to
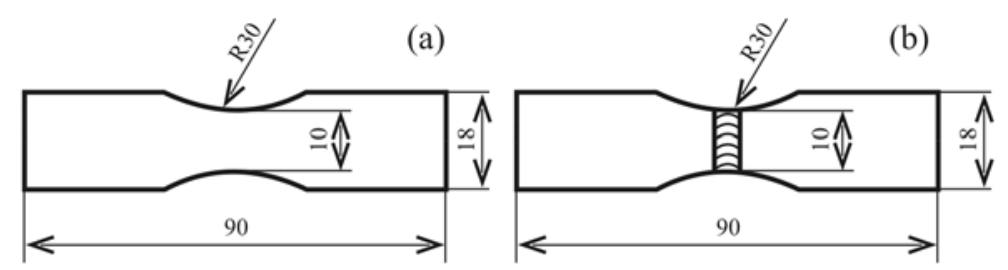

Fig. 2. Fatigue test sample sizes: (a) base metal, (b) FSW test sample. 

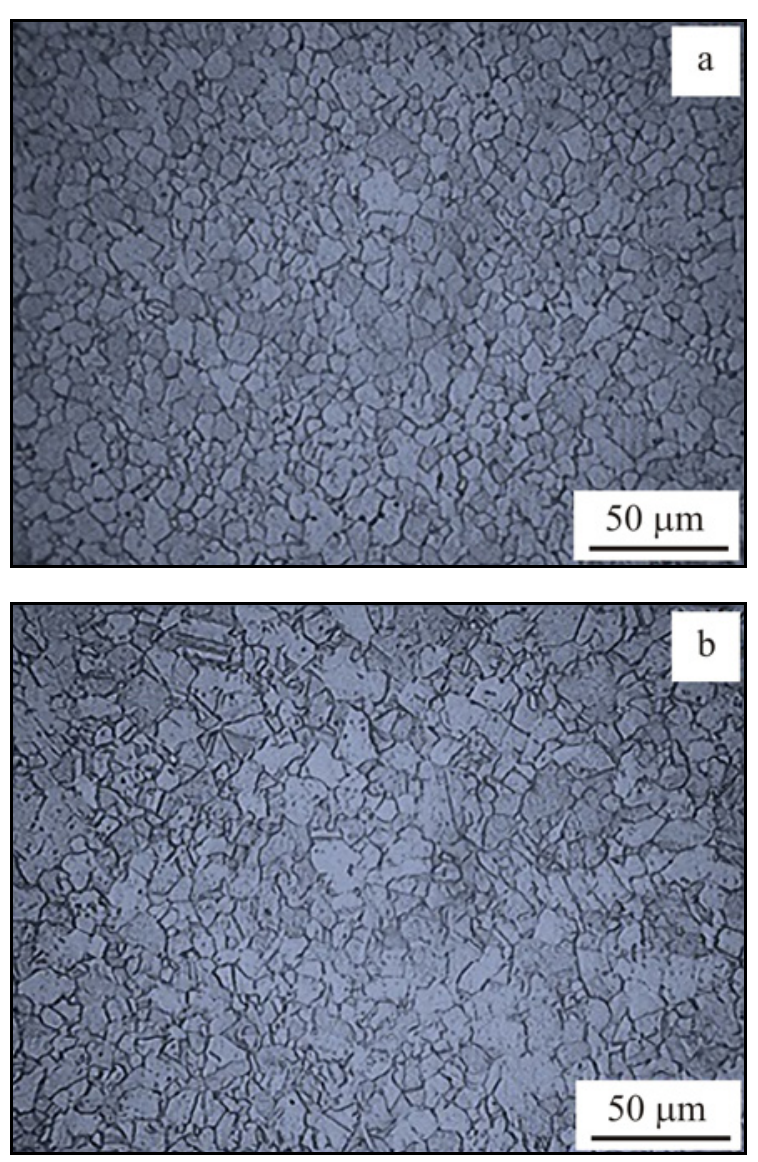

Fig. 4. Effect of rotational speed on the microstructure of NZ: (a) $750 / 20$, (b) $1000 / 20$.

the upper side of the joint. No macro- or microstructural defect was detected on the surfaces of the other samples. Burrs and corrugations were observed on the retreating side (RS) of the welded joints. The corrugations resulted from the plasticizing of the brass alloy due to the frictional heat and accumulation of plasticized material in the direction of rotation with the pressure of shoulder $[3,9,10,13]$.

Figures 4, 5 show the microstructures of nugget zones (NZ). During FSW, heavy plastic deformation was observed especially at the nugget zones. As a result of the frictional heat and plastic deformation during FSW, coarse grains in the base metal transformed into fine equiaxed grains. Based on the fine and equiaxed grains in the NZ of the joints, it can be concluded that dynamic recrystallization occurs during FSW [15-18]. In all samples, while high heat resulted in the recrystallization of the grain structure of the nugget zones, plastic deformation resulted in a homogeneous structure. Figure 4 shows the effect of rotational speed on the microstructure of NZ. Microstructural examination showed that grain size of the welded joints increased with increasing rotational speed due to the effect of $R_{\mathrm{s}} / W_{\mathrm{s}}$ (rotational speed/welding speed) ratio. This ratio has an impact
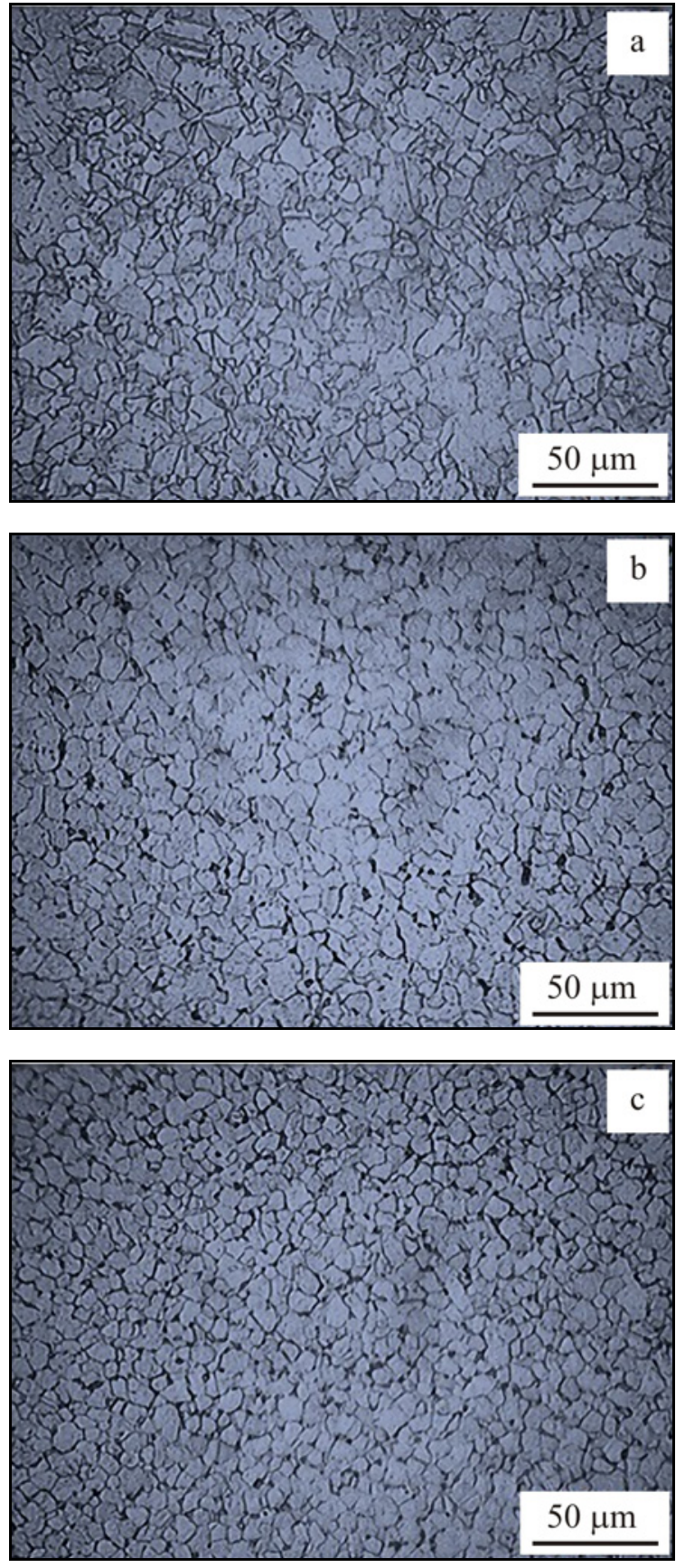

Fig. 5. Effect of welding speed on the microstructure of NZ: (a) 1000/20, (b) 1000/40, and (c) 1000/60.

on heat input in FSW. The equation of heat input is as follows $[14,19]$ :

$$
Q=\frac{4}{3} \pi^{2} \mu R_{\mathrm{s}} \operatorname{Pr}^{2}
$$

where $Q$ is the heat input (W), $\mu$ is the friction coefficient, $R_{\mathrm{S}}$ is the rotational speed $\left(\mathrm{rev} \mathrm{s}^{-1}\right), P$ is the vertical pressure $(\mathrm{Pa})$, and $r$ is the radius of tool shoulder $(\mathrm{mm})$. According to the equation, heat input $(Q)$ in 

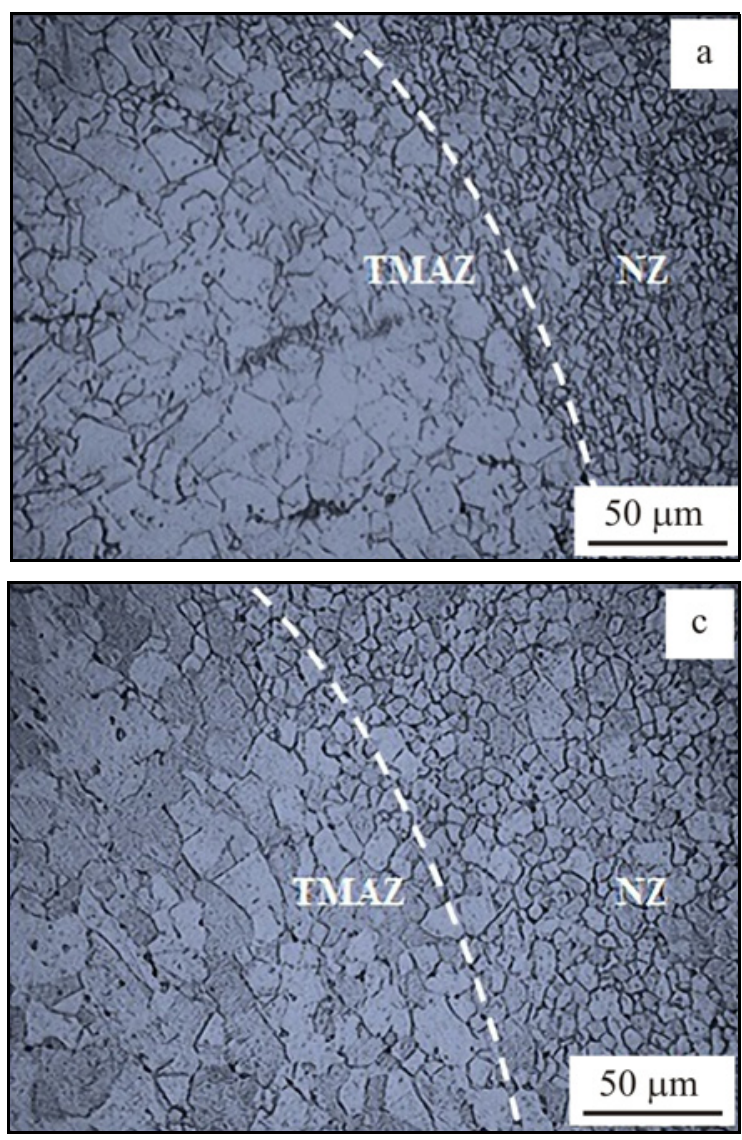

Fig. 6. Micrographs of TMAZs: (a) 750/20

FSW depends on rotational speed. When the welding speed and all other parameters were kept constant, increasing rotational speed had an increasing impact on heat input. Therefore, increasing rotational speed led to an increase in frictional heat on the welded joint. Thus it generated more coarse grains at NZ [14, 20$22]$.

Figure 5 shows the effect of welding speed on the microstructure of NZ. Increasing welding speed affected the grain size of the welded joints. Increasing welding speed resulted in a decrease in the grain size. At the constant rotational speed, increasing welding speed decreased the $R_{\mathrm{s}} / W_{\mathrm{s}}$ ratio. Decreased $R_{\mathrm{s}} / W_{\mathrm{S}}$ ratio reduced the heat input at the welding zone. The recrystallized grains coarsened at a lower level under low frictional heat compared to the high frictional heat $[2,5,23]$. Park et al. [14] reported that $R_{\mathrm{s}} / W_{\mathrm{s}}$ ratio had an effect on heat input and a decrease in this ratio caused a decrease in the size of the micro grains at NZ.

Figure 6 shows the microstructure of the thermo-mechanically affected zones (TMAZ). The microstructure images show the transition zone on the advancing side (AS) of the welded joints. The microstructural examination revealed that TMAZ had a totally different structure than NZ in terms of the grain size. A comparison of Fig. 6a and 6b showed more coarse grains in
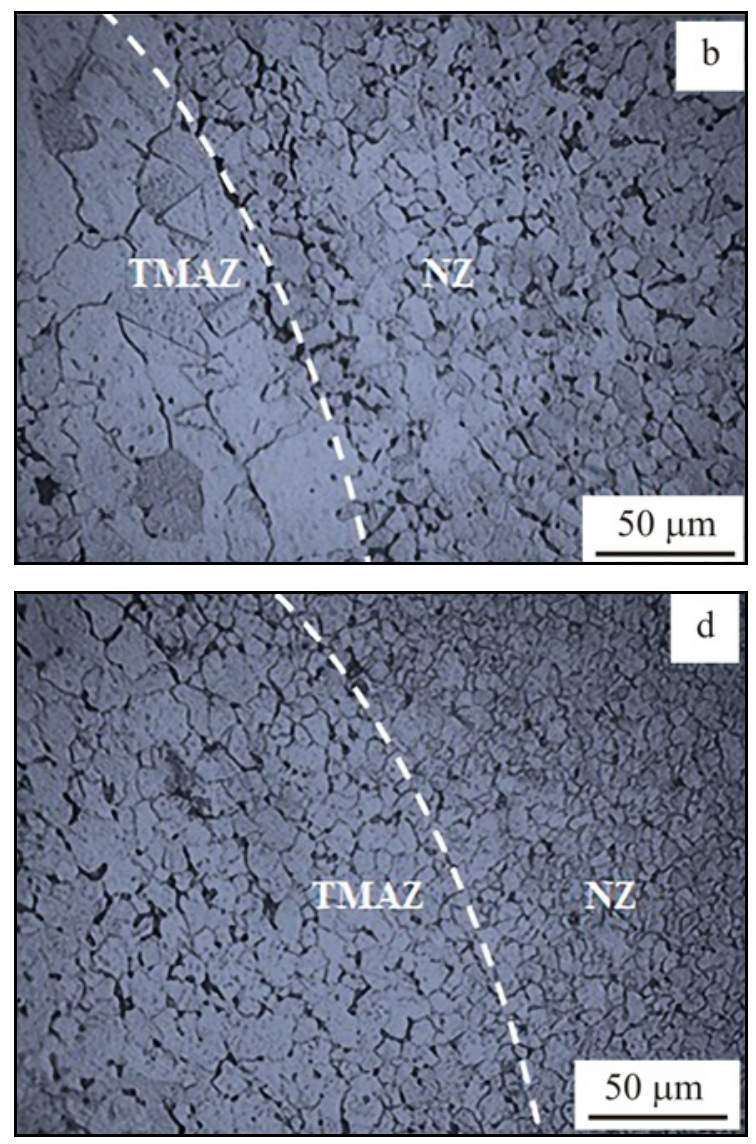

(b) $1000 / 20$, (c) 1000/40, and (d) 1000/60.

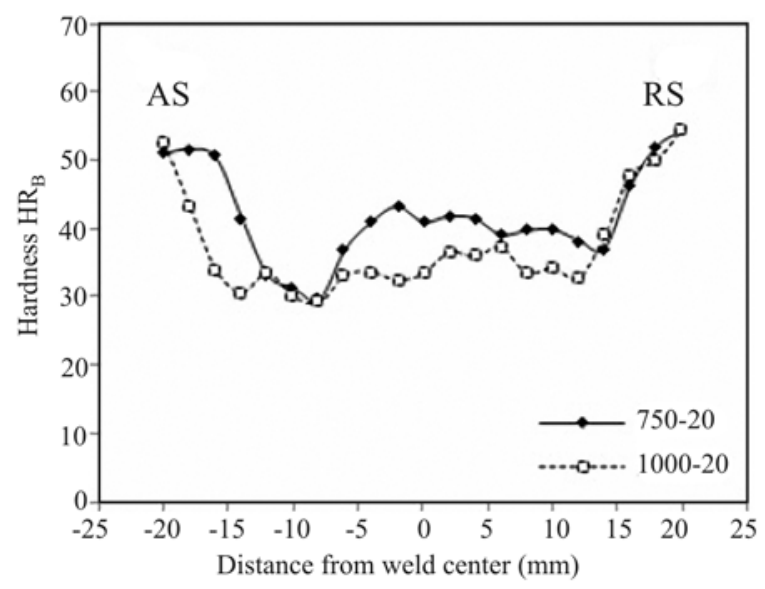

Fig. 7. Effect of rotational speed on hardness.

TMAZ of the sample $1000 / 20$ compared to the sample $750 / 20$. Increasing rotational speed and almost no deformation at TMAZ were the effective parameters of this situation. It was also observed that the grain size at TMAZ decreased with increasing welding speed (Figs. 6b-d).

\subsection{Hardness}

Figure 7 shows the effect of rotational speed on the 


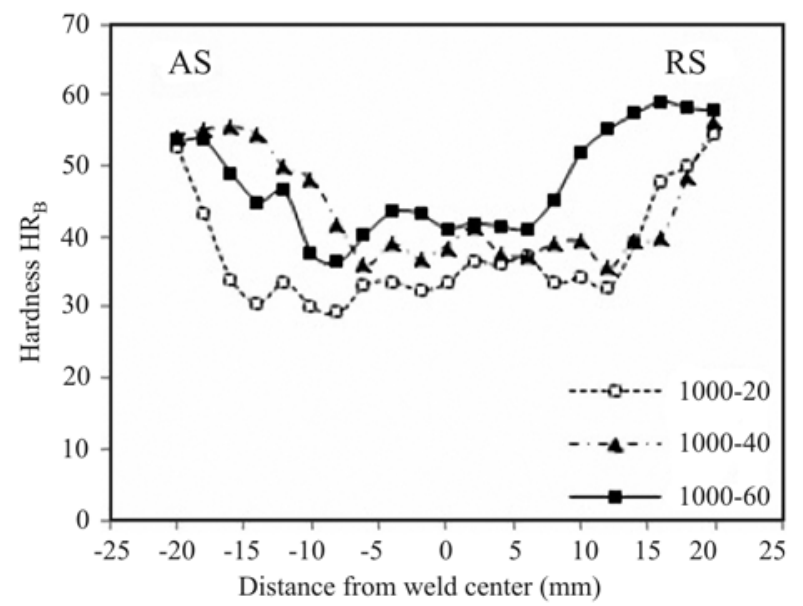

Fig. 8. Effect of welding speed on hardness.

hardness of welded joints. The hardness was found to be $41 \mathrm{HR}_{\mathrm{B}}$ and $33.4 \mathrm{HR}_{\mathrm{B}}$ at $\mathrm{NZ}$ of the sample $750 / 20$ and $1000 / 20$, respectively. The lowest hardness value at both welded joints was detected on the advancing side, at a distance 8-10 $\mathrm{mm}$ away from the weld center. The zone with the lowest hardness was near the TMAZ-NZ interface, and mostly at TMAZ. The lowest hardness value was $29.6 \mathrm{HR}_{\mathrm{B}}$ in the sample $750 / 20$, and $29.2 \mathrm{HR}_{\mathrm{B}}$ in the sample $1000 / 20$. Due to the increasing heat input and the resultant coarse-grained microstructure at the high rotational speed, the sample 1000/20 had a lower hardness at the welded joint. The hardness increased away from the weld center to the base material. This was associated with the lower heat input at these locations.

Figure 8 shows the effect of welding speed on the hardness of the welded joints. The hardness at NZ increased with increasing welding speed. The hardness was found to be $33.4 \mathrm{HR}_{\mathrm{B}}, 38.7 \mathrm{HR}_{\mathrm{B}}$, and $41.2 \mathrm{HR}_{\mathrm{B}}$ at NZ of the sample $1000 / 20$, the sample $1000 / 40$, and the sample $1000 / 60$, respectively. Low heat input occurring as a result of high welding speed both increased the hardness at NZ of the sample 1000/60 and caused a decrease in hardness in a narrower zone. The lowest hardness value was detected on the advancing side at a distance $6-10 \mathrm{~mm}$ away from the weld center. The zone with the lowest hardness was near TMAZ-NZ interface, and mostly at TMAZ. The lowest hardness values were $29.2 \mathrm{HR}_{\mathrm{B}}, 36.1 \mathrm{HR}_{\mathrm{B}}$, and $36.4 \mathrm{HR}_{\mathrm{B}}$ in the samples $1000 / 20,1000 / 40$, and $1000 / 60$, respectively. In all three samples, it was observed that hardness increased away from the weld center to the base material. Çam et al. [5] reported that hardness of the CuZn37 brass plates after FSW process was lower compared to the base material and the lowest hardness was observed at a distance $10 \mathrm{~mm}$ away from the weld center. Moreover, they indicated that the welding speed was an effective parameter for the hardness profiles of the welded joints.

\subsection{Fatigue properties}

Figure 9 shows the results of the bending fatigue test of the samples joined by using FSW process. According to the figure, the lowest fatigue life values were observed in the sample $1000 / 20$. In the sample $1000 / 20$, the formation of tunnel defect occurred as a result of the imbalance in $R_{\mathrm{S}} / W_{\mathrm{s}}$ ratio. Tunnel defect produced a notch effect, thus resulting in the shortest fatigue life. Besides, a heat input increase based on $R_{\mathrm{s}} / W_{\mathrm{s}}$ ratio decreased the hardness profile of the welded joint. It was expected that the materials with high hardness values had higher fatigue life [24-26]. The fracture in the samples 750/20 and 1000/20 usually occurred on RS of the weld center (Fig. 10). The fracture in samples $750 / 20$ and $1000 / 20$ began at the weld root (Figs. 11b,c). According to the fatigue life

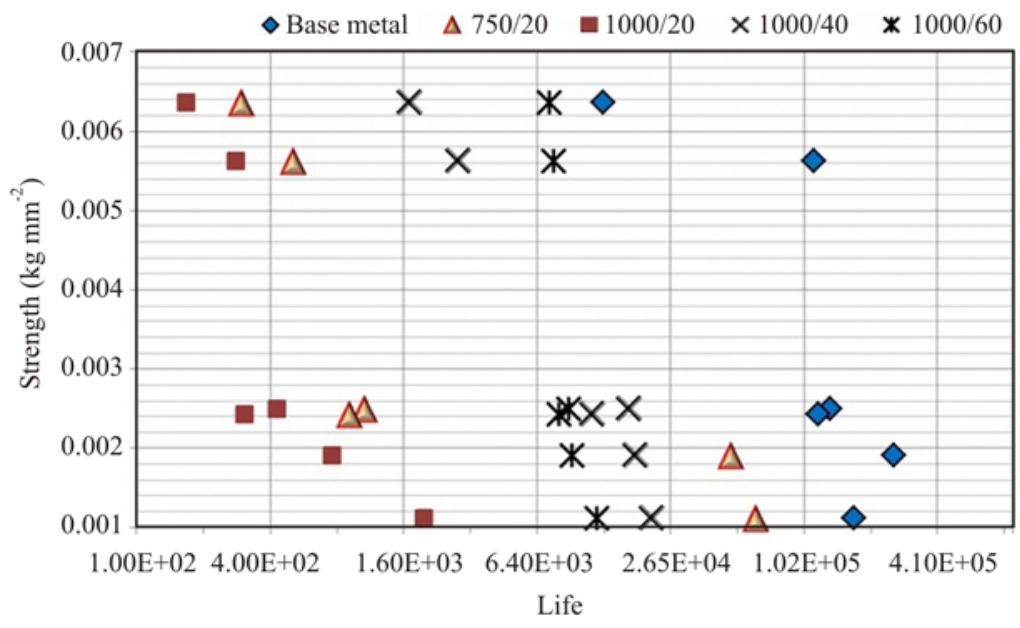

Fig. 9. Fatigue test results for welded joints. 


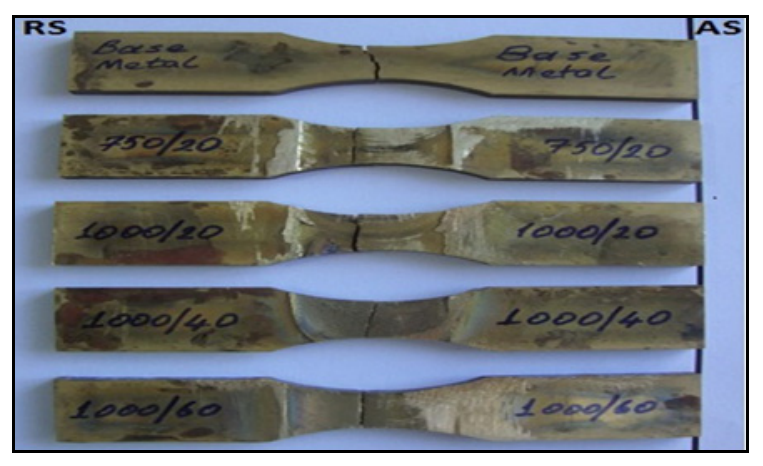

Fig. 10. The macro images of fatigue fracture zones. analysis of the sample $1000 / 20$, the sample $1000 / 40$, and the sample 1000/60 which were joined at a constant rotational speed and different welding speeds, the lowest fatigue life values were observed in the sample 1000/20. The reasons were the high heat input, wide welding zone, low hardness, and formation of tunnel defect (Fig. 11c).

At the constant rotational speed, increasing welding speed had a decreasing impact on heat input and decreasing heat input resulted in a narrow welding zone and higher hardness. It was expected that materials with high hardness and narrow weld zones had longer fatigue life [24-26]. While the best fatigue life results at low strain rates were obtained in samples
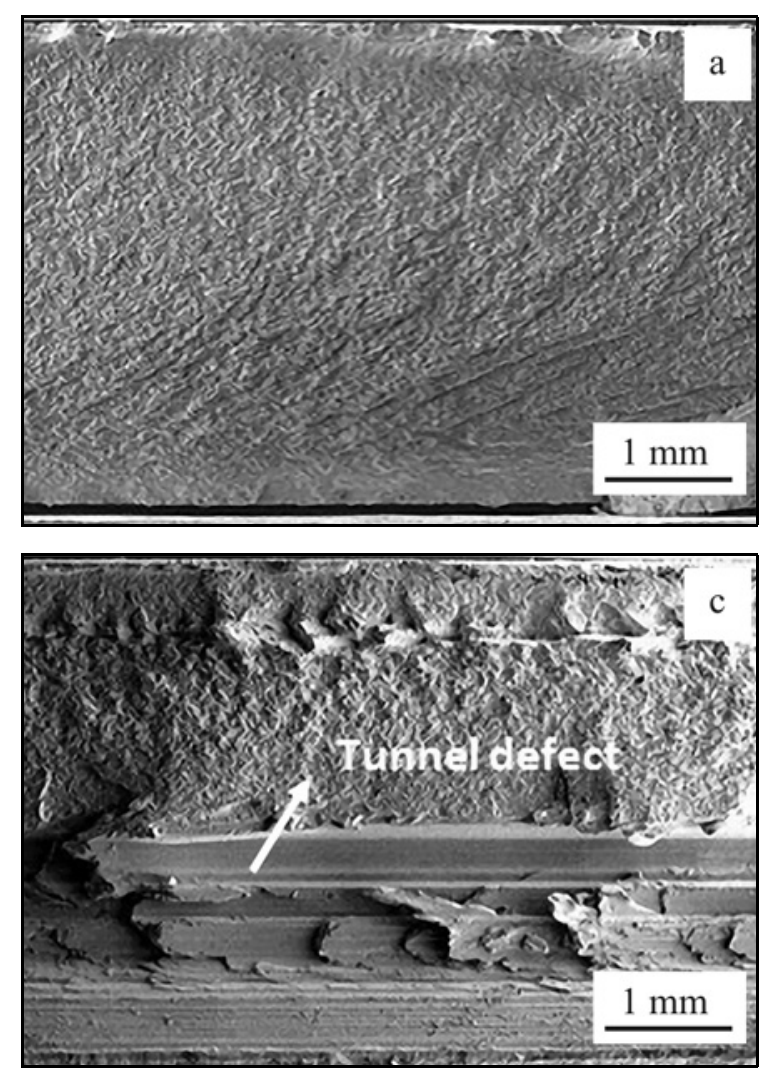
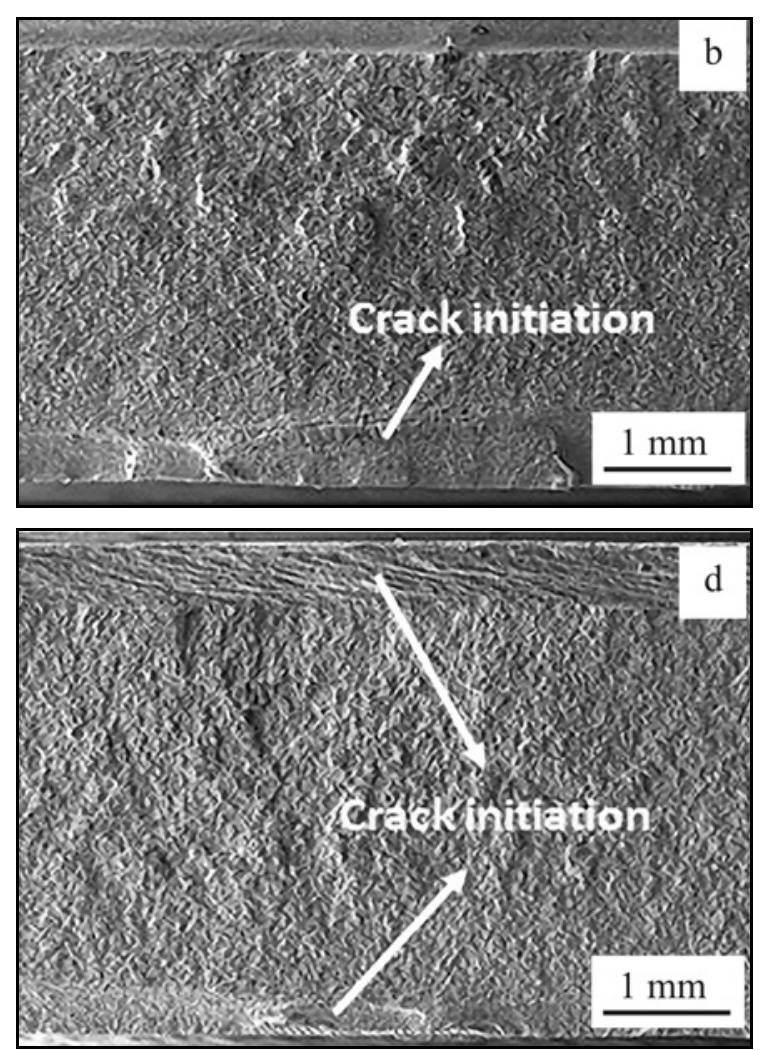

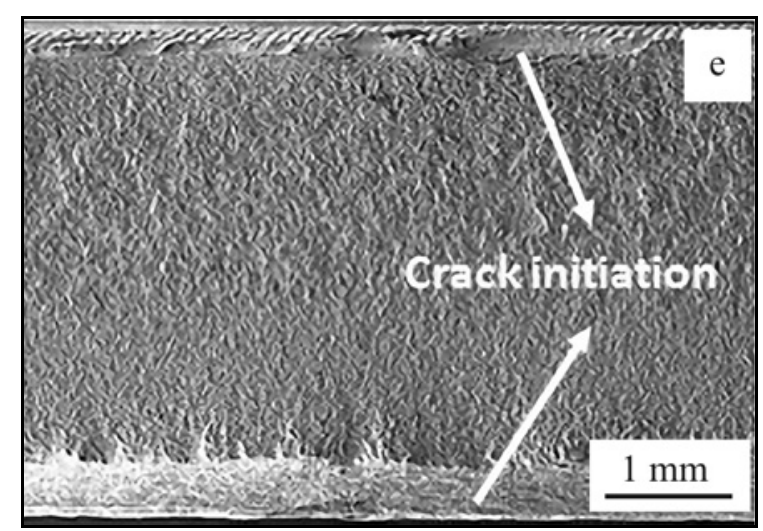

Fig. 11. SEM images of fracture surface: (a) base metal, (b) 750/20, (c) 1000/20, (d) 1000/40, and (e) 1000/60. 
joined at a rotational speed of $750 \mathrm{rpm}$ and a welding speed of $20 \mathrm{~mm} \mathrm{~min}^{-1}$, those at high strain rates were obtained in the samples joined at a rotational speed of $1000 \mathrm{rpm}$ and a welding speed of $60 \mathrm{~mm} \mathrm{~min}^{-1}$. In the samples $1000 / 40$ and $1000 / 60$, fracture occurred on the retreating side of NZ (Fig. 10). Fracture surface analysis of these samples showed that cracks were topdown and bottom-up and they occurred as a result of the reduction in the cross-section (Figs. 11d,e).

\section{Conclusions}

The main conclusions of this study are summarized below:

1. High heat and severe deformations resulted in recrystallization of coarse grains at NZ, thus resulting in finer grained structures.

2. At the constant welding speed, grain size at NZ and TMAZ increased with increasing rotational speed. At the constant rotational speed, grain size at NZ and TMAZ decreased with increasing welding speed.

3. Decreasing hardness values were observed at the weld zones of all samples. At the constant welding speed, increasing rotational speed caused a decrease in hardness at a larger weld zone. On the other hand, at the constant rotational speed, increasing welding speed caused a decrease in hardness at a narrower weld zone.

4. While the best fatigue life results at low strain rates were obtained in the samples joined at a rotational speed of $750 \mathrm{rpm}$ and a welding speed of $20 \mathrm{~mm} \mathrm{~min}^{-1}$, those at high strain rates were obtained in the samples joined at a rotational speed of $1000 \mathrm{rpm}$ and a welding speed of $60 \mathrm{~mm} \mathrm{~min}^{-1}$. Fatigue was usually observed on the retreating sides (RS) of the samples.

\section{References}

[1] Sun, Y. F., Xu, N., Fujii, H.: Mater. Sci. Eng. A, 589, 2014, p. 228. doi:10.1016/i.msea.2013.09.094

[2] Xie, G. M., Ma, Z. Y., Geng, L.: Mater. Trans., 49, 2008, p. 1698. doi:10.2320/matertrans.MRP2008089

[3] Erdem, M.: Int. J. Adv. Manuf. Technol., 76, 2015, p. 1583. doi:10.1007/s00170-014-6387-1

[4] Heidarzadeh, A, Saeid, T.: Data in Brief, 5, 2015, p. 1022. doi:10.1016/j.dib.2015.11.013
[5] Çam, G., Mistikoglu, S., Pakdil, M.: Welding Journal, 88, 2009, p. 225.

[6] Barlas, Z., Uzun, H.: J. Achiev. Mater. Manuf. Eng., 30, 2008, p. 182.

[7] Khodaverdizadeh, H., Heidarzadeh, A., Saeid, T.: Mater. Design, 45, 2013, p. 265. doi:org/10.1016/i.matdes.2012.09.010

[8] Çevik, B., Özçatalbaş, Y., Gülenç, B.: Materials Testing, 58, 2016, p. 36. doi:10.3139/120.110816

[9] Çevik, B., Özçatalbaş, Y., Gülenç, B.: Practical Metallography, 53, 2016, p. 6. doi:10.3139/147.110363

[10] Kurt, A., Boz, M., Özdemir, M.: J. Fac. Eng. Arch. Gazi Univ., 19, 2004, p. 191.

[11] Mahoney, M. W., Rhodes, C. G., Flintoff, J. G., Spurling, R. A., Bingel, W. H.: Metall. Mater. Trans. A, 29, 1998, p. 1955. doi:10.1007/s11661-998-0021-5

[12] Moghaddam, M. S., Parvizi, R., Haddad-Sabzevar, M., Davoodi, A.: Mater. Design, 32, 2011, p. 2749. doi:10.1016/j.matdes.2011.01.015

[13] Meran, C.: Mater. Design, 27, 2006, p. 719. doi:10.1016/i.matdes.2005.05.006

[14] Park, H. S., Kimura, T., Murakamic, T., Nagano, Y., Nakata, K., Ushio, M.: Mater. Sci. Eng. A, 371, 2004, p. 160. doi:10.1016/j.msea.2003.11.030

[15] Heidarzadeh, A., Saeid, T.: Mater. Sci. Eng. A, 649, 2016, p. 349. doi:10.1016/j.msea.2015.10.012

[16] Heidarzadeh, A., Kazemi-Choobi, K., Hanifian, H., Asadi, P.: In: Advances in Friction-Stir Welding and Processing. 1st Edition. Amsterdam, Elsevier, Woodhead Publishing 2014. doi:10.1533/9780857094551.65

[17] Heidarzadeh, A., Saeid, T.: Rare Met., 35, 2016, p. 1. doi:10.1007/s12598-016-0704-9

[18] Khodaverdizadeh, H., Mahmoudi, A., Heidarzadeh, A., Nazari, E.: Mater. Design, 35, 2012, p. 330. doi:10.1016/j.matdes.2011.09.058

[19] Uygur, I.: Arch. Metall. Mater., 57, 2012, p. 53. doi:10.2478/v10172-011-0152-3

[20] Heidarzadeh, A., Saeid, T.: Mater. Design, 52, 2013, p. 1077. doi:10.1016/j.mates.2013.06.068

[21] Heidarzadeh, A., Jabbari, M., Esmaily, M.: Int. J. Adv. Manuf. Technol., 77, 2015, p. 1819. doi:10.1007/s00170-014-6543-7

[22] Farrokhi, H., Heidarzadeh, A., Saeid, T.: Sci. Technol. Weld. Join., 18, 2013, p. 692. doi:10.1179/1362171813Y.0000000148

[23] Heidarzadeh, A., Saeid, T., Khodaverdizadeh, H., Mahmoudi, A., Nazari, E.: Metall. Mater. Trans. B, 44, 2013, p. 175. doi:10.1007/s11663-012-9755-y

[24] Dawes, C. J.: Friction Stir Welding. Cambridge, The Welding Institute 1999.

[25] Şik, A.: Effects of Gas Compositions on Mechanical Properties of MIG/MAG Welded Automobile Body Sheets. [Ph.D. Thesis]. Ankara, Gazi University 2002.

[26] Şik, A.: Journal of Polytechnic, 9, 2006, p. 125. 